\title{
Acetylcholine Attenuates Hydrogen Peroxide-Induced Intracellular Calcium Dyshomeostasis Through Both Muscarinic and Nicotinic Receptors in Cardiomyocytes
}

\author{
Siripong Palee ${ }^{a, b, d}$ Nattayaporn Apaijai ${ }^{b, c, d} \quad$ Krekwit Shinlapawittayatorn ${ }^{b, c, d}$ \\ Siriporn C. Chattipakorn ${ }^{\mathrm{b}, \mathrm{d}, \mathrm{e}}$ Nipon Chattipakorn ${ }^{\mathrm{b}, \mathrm{c}, \mathrm{d}}$
}

\begin{abstract}
aSchool of Medicine, Mae Fah Luang University, Chiang Rai, ${ }^{b}$ Cardiac Electrophysiology Research and Training Center, Faculty of Medicine, Chiang Mai University, Chiang Mai, 'Cardiac Electrophysiology Unit, Department of Physiology, Faculty of Medicine, Chiang Mai University, Chiang Mai, ${ }^{d}$ Center of Excellence in Cardiac Electrophysiology, Chiang Mai University, Chiang Mai, eDepartment of Oral Biology and Diagnostic Science, Faculty of Dentistry, Chiang Mai University, Chiang Mai, Thailand
\end{abstract}

\section{Key Words}

Acetylcholine • Oxidative stress $\bullet$ Hydrogen peroxide $•$ Calcium transient

\begin{abstract}
Background/Aims: Oxidative stress induced intracellular $\mathrm{Ca}^{2+}$ overload plays an important role in the pathophysiology of several heart diseases. Acetylcholine (ACh) has been shown to suppress reactive oxygen species generation during oxidative stress. However, there is little information regarding the effects of $\mathrm{ACh}$ on the intracellular $\mathrm{Ca}^{2+}$ regulation in the presence of oxidative stress. Therefore, we investigated the effects of $\mathrm{ACh}$ applied before or after hydrogen peroxide $\left(\mathrm{H}_{2} \mathrm{O}_{2}\right)$ treatment on the intracellular $\mathrm{Ca}^{2+}$ regulation in isolated cardiomyocytes. Methods: Single ventricular myocytes were isolated from the male Wistar rats for the intracellular $\mathrm{Ca}^{2+}$ transient study by a fluorimetric ratio technique. Results: $\mathrm{H}_{2} \mathrm{O}_{2}$ significantly decreased both of intracellular $\mathrm{Ca}^{2+}$ transient amplitude and decay rate. ACh applied before, but not after, $\mathrm{H}_{2} \mathrm{O}_{2}$ treatment attenuated the reduction of intracellular $\mathrm{Ca}^{2+}$ transient amplitude and decay rate. Both atropine (a muscarinic acetylcholine receptor blocker) and mecamylamine (a nicotinic acetylcholine receptor blocker) significantly decreased the protective effects of acetylcholine on the intracellular $\mathrm{Ca}^{2+}$ regulation. Moreover, the combination of atropine and mecamylamine completely abolished the protective effects of acetylcholine on intracellular $\mathrm{Ca}^{2+}$ transient amplitude and decay rate. Conclusion: $\mathrm{ACh}$ pretreatment attenuates $\mathrm{H}_{2} \mathrm{O}_{2}-$ induced intracellular $\mathrm{Ca}^{2+}$ dyshomeostasis through both muscarinic and nicotinic receptors.
\end{abstract}




\section{Cellular Physiology Cell Physiol Biochem 2016;39:341-349

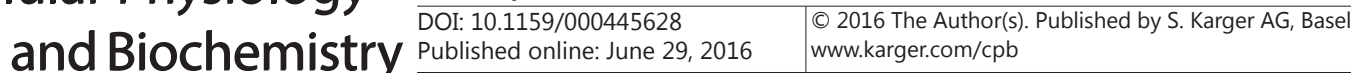 \\ Palee et al.: Acetylcholine Attenuates $\mathrm{H}_{2} \mathrm{O}_{2}$-Induced Calcium Dyshomeostasis}

\section{Introduction}

Oxidative stress has been shown to play an important role in the pathophysiology of several pathological conditions including acute myocardial infarction (MI) [1-3]. In MI patients, timely myocardial reperfusion of coronary blood flow is necessary to resuscitate the ischemic or hypoxic myocardium $[4,5]$. Reperfusion facilitates cardiac myocytes salvage and decreases cardiac morbidity and mortality. However, reperfusion of an ischemic myocardium may result in paradoxical cardiac dysfunction, a phenomenon known as "ischemia/reperfusion (I/R) injury" [5]. The hydrogen peroxide $\left(\mathrm{H}_{2} \mathrm{O}_{2}\right)$ is one of the key mediators underlying cellular oxidative stress during I/R [5]. The formation of $\mathrm{H}_{2} \mathrm{O}_{2}$ during $\mathrm{I} / \mathrm{R}$ injury results in intracellular $\mathrm{Ca}^{2+}$ overload due to increased lipid peroxidation and sulfhydryl group oxidation in the I/R heart [1]. Therefore, any therapeutic approach which can prevent intracellular $\mathrm{Ca}^{2+}$ overload and improves intracellular $\mathrm{Ca}^{2+}$ regulation would be beneficial for reperfused heart.

Acetylcholine (ACh) has been shown to suppress reactive oxygen species generation during oxidative stress [6,7]. Moreover, previous studies reported that parasympathetic activation by vagus nerve stimulation (VNS)-induced ACh release exerted cardioprotective effects against I/R injury [8-11]. Moreover, our recent study demonstrated that VNS reduced the occurrence of ventricular fibrillation and decreases myocardial infarction size in I/R model $[12,13]$. Furthermore, VNS could improve cardiac mitochondrial function which was impaired in I/R hearts [12]. Despite these beneficial effects, there is little information regarding the effects of $\mathrm{ACh}$ on the intracellular $\mathrm{Ca}^{2+}$ regulation in the presence of oxidative stress. In this study, we investigated the effects of ACh applied before or after $\mathrm{H}_{2} \mathrm{O}_{2}$ treatment on intracellular calcium regulation in isolated cardiomyocytes. We hypothesized that ACh can attenuate intracellular $\mathrm{Ca}^{2+}$ dyshomeostasis caused by $\mathrm{H}_{2} \mathrm{O}_{2}$ in cardiomyocytes.

\section{Materials and Methods}

\section{Animal preparation and study protocol}

This study was approved by the Institutional Animal Care and Use Committees of the Faculty of Medicine, Chiang Mai University. All the animals were fed with normal rat chow and water ad libitum before the study. Male Wistar rats (250-300 g) were used. The rats were deeply anesthesized with thiopental (0.5 $\mathrm{mg} / \mathrm{kg}$; Research institute of antibiotics and biotransformations, Roztoky, Czech Republic) after which the hearts were removed for single ventricular myocyte isolation [14]. The isolated cardiomyocytes were used in each study protocol for the measurement of intracellular $\mathrm{Ca}^{2+}$ transient. Data were compared between the experimental groups.

In the protocol 1, cardiomyocytes were divided into 5 groups ( $\mathrm{n}=8$ cells/rat and 8 rats/group) as shown in Fig. 1A. Cardiomyocytes were divided into 5 groups. In groups I, cardiomyocytes were treated with normal saline solution (NSS) for 5 minutes as a control group. Group II was treated with ACh (10 $\mu \mathrm{M}$ ) (Acetylcholine chloride, Sigma-Aldrich, St. Louis, MO, USA) for 5 minutes, and Group III was treated with NSS for 2 minutes followed by $\mathrm{H}_{2} \mathrm{O}_{2}(2 \mathrm{mM})$ for 3 minutes. Group IV was treated with a muscarinic receptor blocker, atropine $(1 \mu \mathrm{M})$ for 5 minutes, and Group V was treated with a nicotinic receptor blocker mecamylamine $(1 \mu \mathrm{M})$ (Sigma-Aldrich, St. Louis, MO, USA) for 5 minutes. The real-time $\mathrm{Ca}^{2+}$ transient measurement was performed at the beginning of the study (baseline) and at the end of treatment in each group.

In protocol 2, cardiomyocytes were divided into 5 groups ( $\mathrm{n}=8$ cells/rat and 8 rats/group) as shown in Fig. 1B. Cardiomyocytes were divided into 5 groups. In groups I, they were treated with NSS for 10 minutes followed by $\mathrm{H}_{2} \mathrm{O}_{2}(2 \mathrm{mM})$ for 3 minutes and served as a control group. Group II was treated with NSS for 5 minutes followed by ACh $(10 \mu \mathrm{M})$ for 5 minutes followed by $\mathrm{H}_{2} \mathrm{O}_{2}(2 \mathrm{mM})$ for 3 minutes. Group III was treated with atropine $(1 \mu \mathrm{M})$ for 5 minutes followed by ACh $(10 \mu \mathrm{M})$ for 5 minutes and then $\mathrm{H}_{2} \mathrm{O}_{2}$ $(2 \mathrm{mM})$ for 3 minutes. Group IV was treated with a mecamylamine $(1 \mu \mathrm{M})$ for 5 minutes followed by ACh $(10 \mu \mathrm{M})$ for 5 minutes and then $\mathrm{H}_{2} \mathrm{O}_{2}(2 \mathrm{mM})$ for 3 minutes. Group V was treated with a mecamylamine (1 $\mu \mathrm{M})$ and atropine $(1 \mu \mathrm{M})$ for 5 minutes followed by ACh $(10 \mu \mathrm{M})$ for 5 minutes and then $\mathrm{H}_{2} \mathrm{O}_{2}(2 \mathrm{mM})$ for 3 


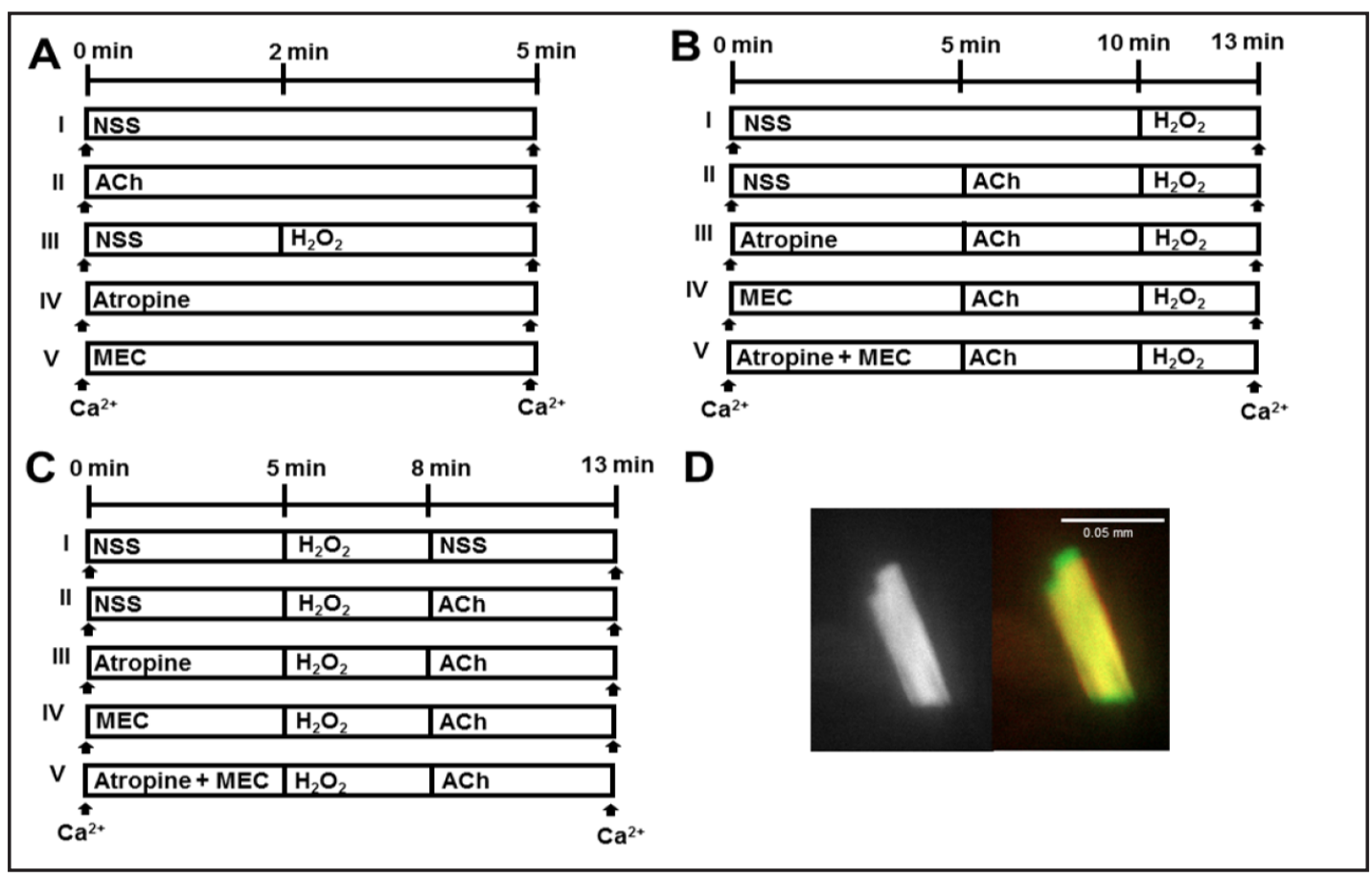

Fig. 1. Experimental groups and the treatment protocol of protocol 1 (A), protocol 2: pre-treatment groups (B), protocol 3: post-treatment groups (C), Cardiac myocytes loaded with fluorescent dye Fura-2/AM (D). NSS=normal saline solution, $\mathrm{ACh}=$ acetylcholine, $\mathrm{MEC}=$ mecamylamine, $\mathrm{H}_{2} \mathrm{O}_{2}=$ hydrogen peroxide, $\mathrm{Ca}^{2+}=$ intracellular calcium measurement.

minutes. The real-time $\mathrm{Ca}^{2+}$ transient measurement was performed at the beginning of the study (baseline) and at the end of treatment in each group.

In protocol 3, cardiomyocytes were divided into 5 groups ( $\mathrm{n}=8$ cells/rat and 8 rats/group) as shown in Fig. 1C. In this protocol, cardiomyocytes were divided into 5 groups. Cardiomyocytes in groups I were treated with NSS for 5 minutes followed by $\mathrm{H}_{2} \mathrm{O}_{2}(2 \mathrm{mM})$ for 3 minutes and then NSS for 5 minutes, and served as a control group. Group II was treated with NSS for 5 minutes followed by $\mathrm{H}_{2} \mathrm{O}_{2}(2 \mathrm{mM})$ for 3 minutes and then ACh $(10 \mu \mathrm{M})$ for 5 minutes, and Group III was treated with atropine $(1 \mu \mathrm{M})$ for 5 minutes followed by $\mathrm{H}_{2} \mathrm{O}_{2}(2 \mathrm{mM})$ for 3 minutes and then ACh $(10 \mu \mathrm{M})$ for 5 minutes. Group IV was treated with a mecamylamine $(1 \mu \mathrm{M})$ for 5 minutes followed by $\mathrm{H}_{2} \mathrm{O}_{2}(2 \mathrm{mM})$ for 3 minutes and then ACh $(10 \mu \mathrm{M})$ for 5 minutes. Group V was treated with the combination of mecamylamine $(1 \mu \mathrm{M})$ and atropine $(1 \mu \mathrm{M})$ for 5 minutes followed by $\mathrm{H}_{2} \mathrm{O}_{2}(2 \mathrm{mM})$ for 3 minutes and then ACh $(10 \mu \mathrm{M})$ for 5 minutes. The real-time $\mathrm{Ca}^{2+}$ measurement was performed at the beginning of the study and after the treatment in all groups.

\section{Calcium transient measurement}

Cardiomyocytes were isolated from the hearts of male Wistar rats using a method described previously [15]. In brief, under deep anesthesia, the heart was immediately removed and placed into a modified Langendroff apparatus. The hearts were perfused with modified Krebs solution $(130 \mathrm{mM} \mathrm{NaCl}$, $4.5 \mathrm{mM} \mathrm{KCl}, 1.4 \mathrm{mM} \mathrm{MgCl}_{2}, 0.4 \mathrm{mM} \mathrm{NaH}_{2} \mathrm{PO}_{4}, 0.75 \mathrm{mM} \mathrm{CaCl}_{2}, 4.2 \mathrm{mM}$ HEPES, $20 \mathrm{mM}$ taurine, $10 \mathrm{mM}$ creatine and $10 \mathrm{mM}$ glucose, $\mathrm{pH} 7.3$ at $37^{\circ} \mathrm{C}$ ) for 5 minutes, followed by calcium-free solution (100 $\mu \mathrm{M}$ EGTA ) for 4 minutes, Tyrode's solution with collagenase $(0.1 \mathrm{mg} / \mathrm{ml})$ for 10 minutes, and modified Krebs solution containing $100 \mu \mathrm{M} \mathrm{CaCl}_{2}$ and $1 \mathrm{mg} / \mathrm{ml}$ type II collagenase for another 8 minutes. The ventricles were removed from the cannula, cut into small pieces and incubated in $10 \mathrm{ml}$ of collagenase solution gassed with $100 \% \mathrm{O}_{2}$ for 7 minutes at $37^{\circ} \mathrm{C}$, with regular triturating. The cardiomyocytes were separated from undigested ventricular tissues by filtering through cell strainer, and were settling into a loose pellet. Then, the supernatant was removed and replaced with modified Krebs solution containing 1\% BSA and $500 \mu \mathrm{M}$ $\mathrm{CaCl}_{2}$. This process was repeated with modified Krebs solution containing $1 \mathrm{mM} \mathrm{CaCl}_{2}$. After this procedure, the cardiomyocytes were ready for recording [15]. The isolated cardiomyocytes were placed in a modified 


\section{Cellular Physiology Cell Physiol Biochem 2016;39:341-349 \\ \begin{tabular}{l|l} 
DOI: 10.1159/000445628 & Ond Biochemistry \\
Published online: June 29, 2016 & $\begin{array}{l}\text { 2016 The Author(s). Published by S. Karger AG, Basel } \\
\text { www.karger.com/cpb }\end{array}$
\end{tabular} \\ Palee et al.: Acetylcholine Attenuates $\mathrm{H}_{2} \mathrm{O}_{2}$-Induced Calcium Dyshomeostasis}

Krebs solution containing $1 \mathrm{mM} \mathrm{CaCl}_{2}$. Intracellular $\mathrm{Ca}^{2+}$ transient were measured using the $\mathrm{CELL}^{\mathrm{R}}$ imaging software (Olympus Soft Imaging Solutions $\mathrm{GmbH}$, Germany). The isolated cardiomyocytes were loaded with Fura-2/AM at the final concentration of $5 \mu \mathrm{M}$ [16] and fluorescent intensity was recorded during electrical pacing (1 Hz, $10 \mathrm{~ms}$ duration, $15 \mathrm{~V}$ ) [17]. The ratio of the emissions wavelengths is directly related to the amount of intracellular $\mathrm{Ca}^{2+}$ [18]. When $\mathrm{Ca}^{2+}$ binds to a ratiometric indicator, it changes the optimum excitation or emission wavelength of the indicator. An elevation of $\mathrm{Ca}^{2+}$ concentration induces an increase in Fura-2 emission fluorescence when the indicator is excited at $340 \mathrm{~nm}$, with a corresponding decrease in fluorescence at $380 \mathrm{~nm}$ excitation $[19,20]$. The experiments were performed in the temperature controlled chamber system at $37^{\circ} \mathrm{C}$. The $\mathrm{H}_{2} \mathrm{O}_{2}$ concentration at $2 \mathrm{mM}$ is a stock solution. The final concentration in the recording chamber is $50 \mu \mathrm{M}$ which is widely used to trigger oxidative stress-induced intracellular $\mathrm{Ca}^{2+}$ dyshomeostasis in cardiomyocytes $[21,22]$. Intracellular $\mathrm{Ca}^{2+}$ transient decay rate which approximates the rate of $\mathrm{Ca}^{2+}$ uptake into the SR by sarco/endoplasmic reticulum $\mathrm{Ca}^{2+}$-ATPase (SERCA), intracellular calcium transient amplitude which approximates the intracellular $\mathrm{Ca}^{2+}$ level during systolic period, and diastolic $\mathrm{Ca}^{2+}$ level which approximates the intracellular $\mathrm{Ca}^{2+}$ level during diastolic period were recorded before and after treatment.

\section{Statistical analysis}

Data were expressed as mean \pm SD. Comparisons of variables were performed using the one-way ANOVA followed by LSD post-hoc test. $P<0.05$ was considered statistically significant.

\section{Results}

$\mathrm{ACh}$ at the concentrations of 1,10 and $100 \mu \mathrm{M}$ did not alter the diastolic $\mathrm{Ca}^{2+}$ level compared to the baseline. However, all concentrations of ACh significantly decreased the intracellular $\mathrm{Ca}^{2+}$ transient amplitude $(0.03 \pm 0.015$ in $1 \mu \mathrm{M}, 0.02 \pm 0.005$ in $10 \mu \mathrm{M}$, and 0.03 \pm 0.005 in $100 \mu \mathrm{M}$, compared to $0.06 \pm 0.001$ at baseline) and $\mathrm{Ca}^{2+}$ transient decay rate $(0.09$ \pm 0.003 in $1 \mu \mathrm{M}, 0.09 \pm 0.004$ in $10 \mu \mathrm{M}$, and $0.06 \pm 0.002$ in $100 \mu \mathrm{M}$, compared to $0.23 \pm$ 0.02 at baseline). In the first protocol, the effects of $\mathrm{H}_{2} \mathrm{O}_{2}, \mathrm{ACh}$, atropine and mecamylamine on the intracellular $\mathrm{Ca}^{2+}$ transient were investigated. $\mathrm{H}_{2} \mathrm{O}_{2}$ significantly decreased both of intracellular $\mathrm{Ca}^{2+}$ transient amplitude (Fig. 2A) and intracellular $\mathrm{Ca}^{2+}$ transient decay rate (Fig. 2B). The intracellular $\mathrm{Ca}^{2+}$ diastolic level was not altered (Fig. 2C) compared to the control group in response to all treatments. In addition, ACh at $10 \mu \mathrm{M}$ significantly decreased the intracellular $\mathrm{Ca}^{2+}$ transient amplitude (Fig. 2A) and $\mathrm{Ca}^{2+}$ transient decay rate (Fig. 2B), but did not alter the level of intracellular diastolic $\mathrm{Ca}^{2+}$ level (Fig. 2C) compared to the control group. However, atropine and mecamylamine did not alter the intracellular $\mathrm{Ca}^{2+}$ transient amplitude, $\mathrm{Ca}^{2+}$ transient decay rate and the intracellular diastolic $\mathrm{Ca}^{2+}$ level. The effect of $\mathrm{H}_{2} \mathrm{O}_{2}$, ACh, atropine and mecamylamine on the intracellular $\mathrm{Ca}^{2+}$ transient tracing shape is shown in Fig. 2D.

In the second protocol, the effects of ACh administered prior to $\mathrm{H}_{2} \mathrm{O}_{2}$ application were investigated. The intracellular $\mathrm{Ca}^{2+}$ transient amplitude was significantly decreased in $\mathrm{H}_{2} \mathrm{O}_{2}$ treated group. However, pretreated with ACh significantly prevent the reduction of the intracellular $\mathrm{Ca}^{2+}$ transient amplitude compare to the $\mathrm{H}_{2} \mathrm{O}_{2}$ treated group, $\mathrm{p}<0.05$ (Fig. 3A). Furthermore, pretreated with ACh significantly increased the intracellular $\mathrm{Ca}^{2+}$ transient decay rate compared to the $\mathrm{H}_{2} \mathrm{O}_{2}$ treated group (Fig. 2B). However, in all experimental groups, ACh did not alter the level of intracellular diastolic calcium (Fig. 3C) compared to the $\mathrm{H}_{2} \mathrm{O}_{2}$ treated group. The protective effect of ACh was reduced when cardiomyocytes were exposed to the muscarinic receptor blocker (atropine) and nicotinic receptor blocker (mecamylamine) prior to ACh application (Fig. 3B, 3C). Moreover, co-incubation of atropine and mecamylamine completely abolished the cardioprotective effects of ACh on intracellular $\mathrm{Ca}^{2+}$ transient amplitude and decay rate. The effects of $\mathrm{ACh}$ on $\mathrm{Ca}^{2+}$ transient tracing shape is shown in Fig. 3D.

In the third protocol, we investigated the effects of ACh administered after $\mathrm{H}_{2} \mathrm{O}_{2}$ application on intracellular $\mathrm{Ca}^{2+}$ transient. Our results showed that in cardiomyocytes treated 


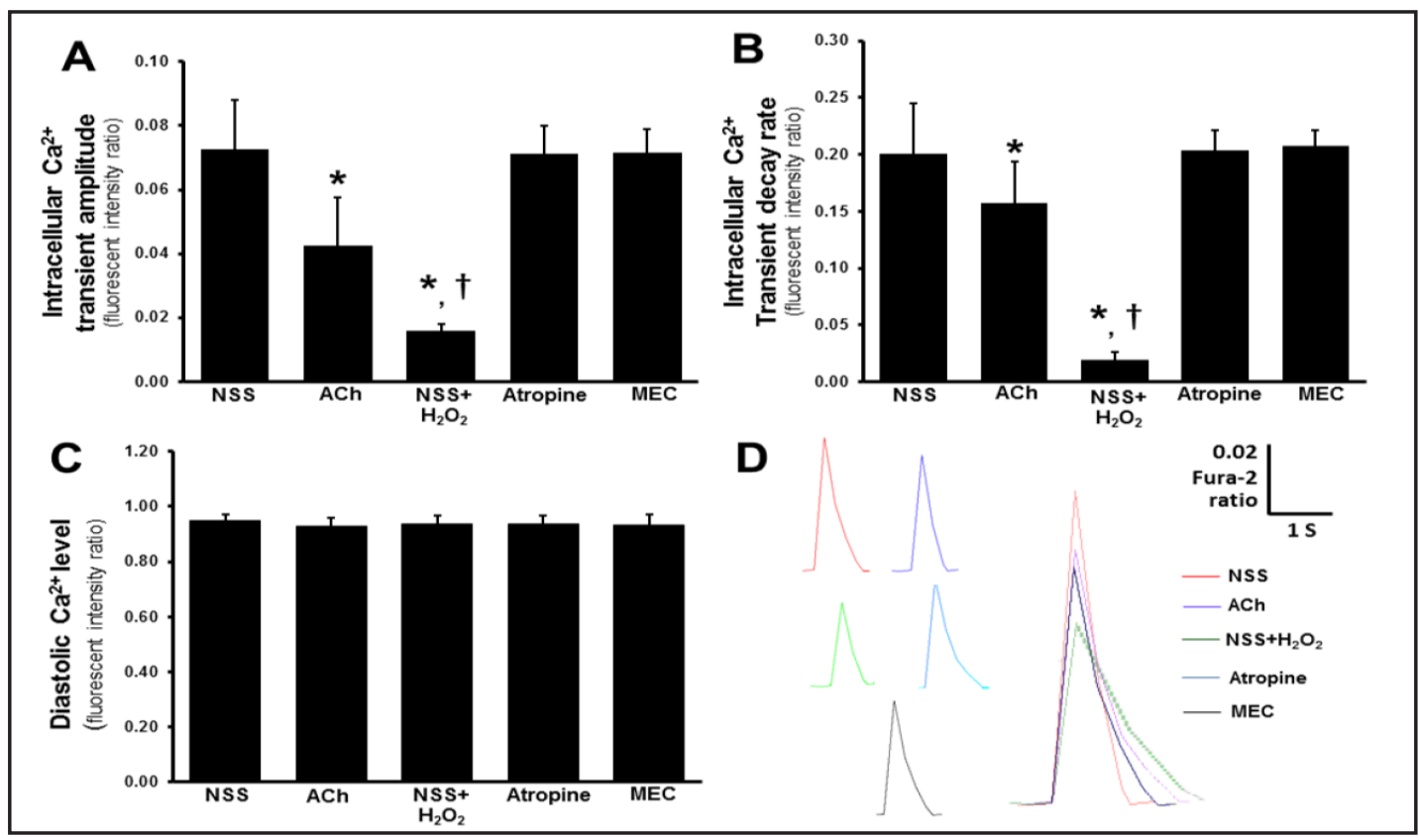

Fig. 2. The effect of acetylcholine, atropine and mecamylamine on the intracellular $\mathrm{Ca}^{2+}$ transient amplitude (A), and intracellular $\mathrm{Ca}^{2+}$ transient decay rate (B) and intracellular diastolic $\mathrm{Ca}^{2+}$ level (C). The effects of ACh on $\mathrm{Ca}^{2+}$ transient tracing shape (D). ${ }^{*} p<0.05$ vs. NSS, $\uparrow p<0.05$ vs. ACh. NSS=normal saline solution, $\mathrm{ACh}=\mathrm{a}-$ cetylcholine, $\mathrm{MEC}=$ mecamylamine, $\mathrm{H}_{2} \mathrm{O}_{2}=$ hydrogen peroxide, $\mathrm{Ca}^{2+}=$ intracellular calcium measurement.

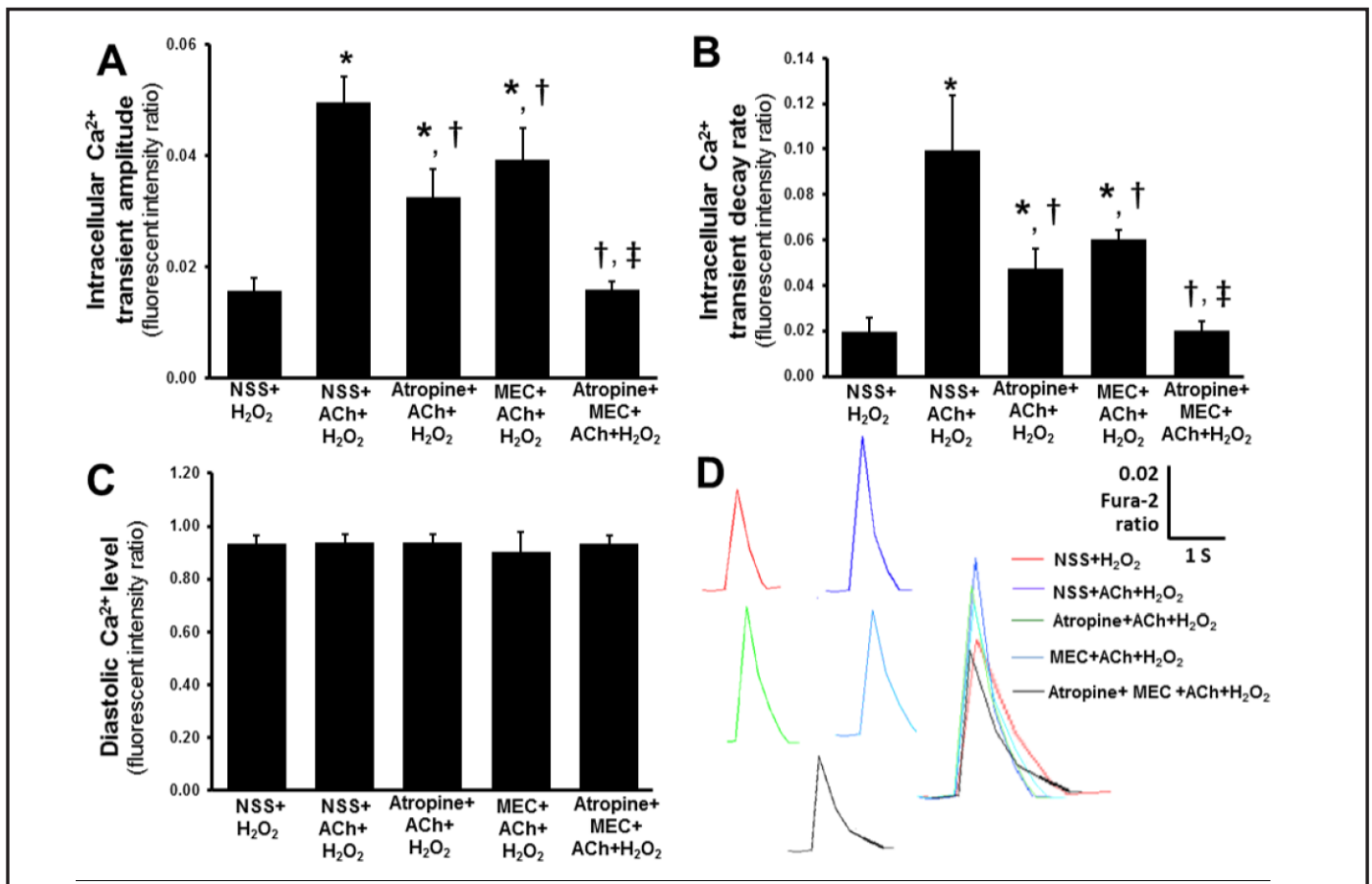

Fig. 3. The effect of pre-treated cardiac myocytes with acetylcholine on the intracellular $\mathrm{Ca}^{2+}$ transient in isolated cardiac myocytes under $\mathrm{H}_{2} \mathrm{O}_{2}$-induced oxidative stress. ACh significantly attenuated the reduction of intracellular $\mathrm{Ca}^{2+}$ transient amplitude (A) and increased intracellular $\mathrm{Ca}^{2+}$ transient decay rate (B) but did not alter intracellular diastolic calcium level (C) compared with $\mathrm{H}_{2} \mathrm{O}_{2}$ group. The protective effects of ACh were abolished by ACh receptor blocking agents. The effects of ACh on $\mathrm{Ca}^{2+}$ transient tracing shape (D). ${ }^{*} p$ $<0.05$ vs. NSS, $\uparrow p<0.05$ vs. $\mathrm{H}_{2} \mathrm{O}_{2}, \neq p<0.05$ vs. ACh. NSS=normal saline solution, $\mathrm{ACh}=$ acetylcholine, $\mathrm{MEC}=-$ mecamylamine, $\mathrm{H}_{2} \mathrm{O}_{2}$ = hydrogen peroxide, $\mathrm{Ca}^{2+}=$ intracellular calcium measurement. 

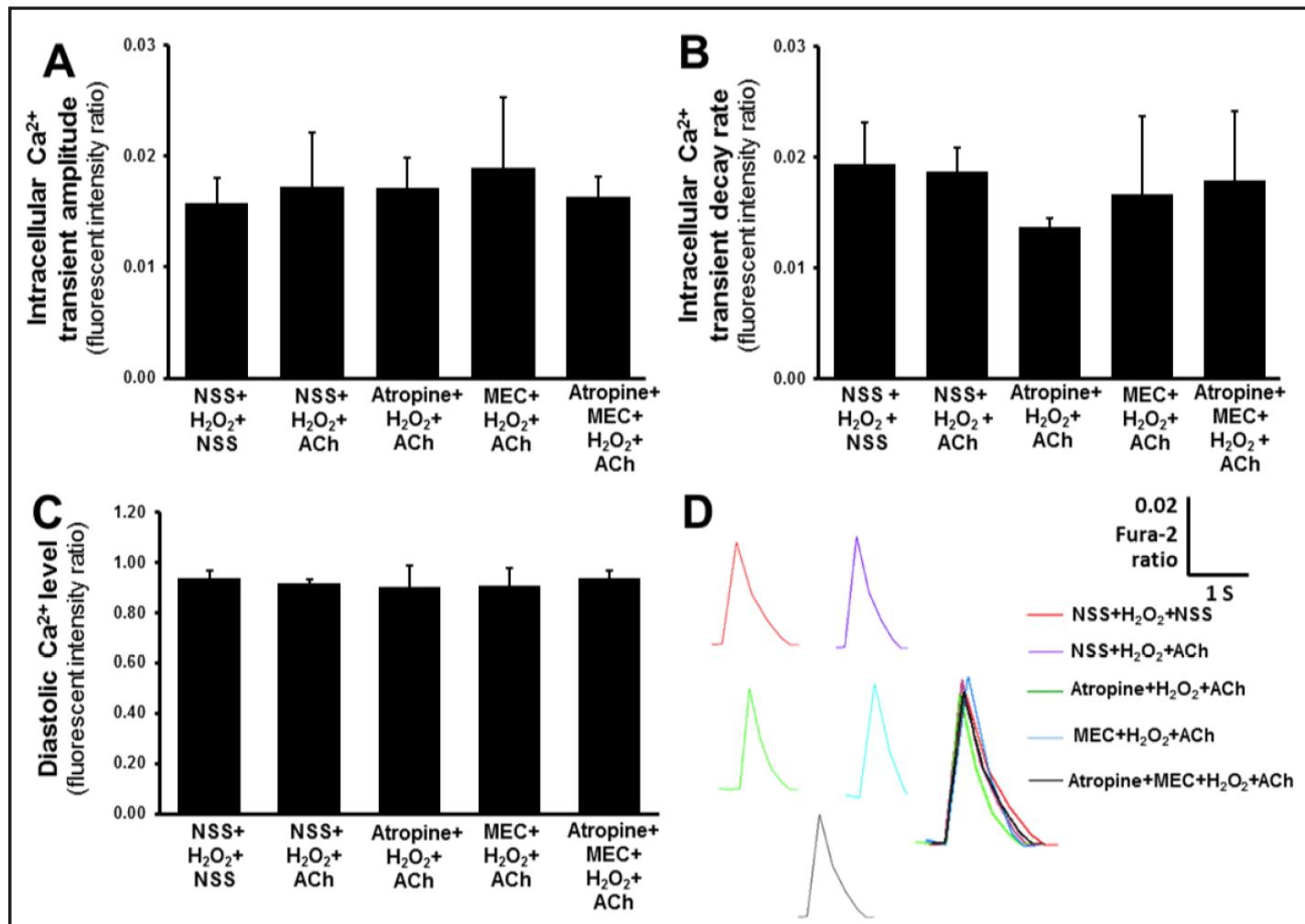

D

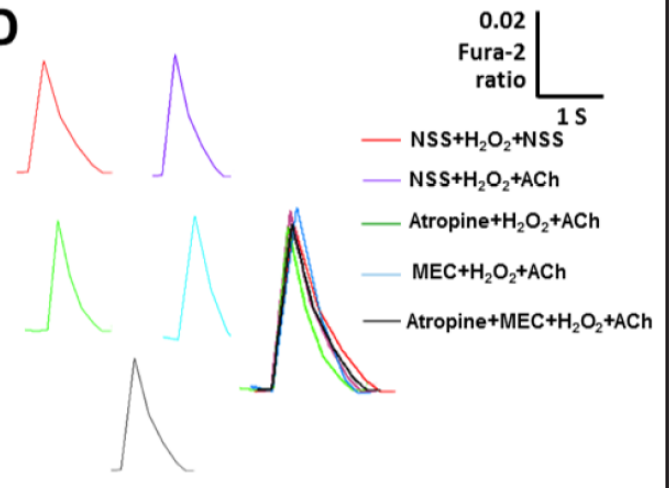

Fig. 4. The effect of post-treated cardiac myocytes with acetylcholine on the intracellular $\mathrm{Ca}^{2+}$ transient in isolated cardiac myocytes $\mathrm{H}_{2} \mathrm{O}_{2}$-induced oxidative stress. ACh did not improve intracellular $\mathrm{Ca}^{2+}$ transient amplitude (A), intracellular $\mathrm{Ca}^{2+}$ transient decay rate (B) and intracellular diastolic $\mathrm{Ca}^{2+}$ level (C) compared with $\mathrm{H}_{2} \mathrm{O}_{2}$ group. The effects of $\mathrm{ACh}$ on $\mathrm{Ca}^{2+}$ transient tracing shape (D). NSS= normal saline solution, $\mathrm{ACh}=$ acetylcholine, $\mathrm{MEC}=$ mecamylamine, $\mathrm{H}_{2} \mathrm{O}_{2}=$ hydrogen peroxide, $\mathrm{Ca}^{2+}=$ intracellular calcium measurement.

with $\mathrm{H}_{2} \mathrm{O}_{2}$ followed by ACh, the intracellular $\mathrm{Ca}^{2+}$ transient amplitude (Fig. 4A), intracellular $\mathrm{Ca}^{2+}$ transient decay rate (Fig. 4B) and the intracellular $\mathrm{Ca}^{2+}$ diastolic level (Fig. 4C) did not alter, compared to cardiomyocyte treated with $\mathrm{H}_{2} \mathrm{O}_{2}$ followed by NSS. Furthermore, atropine and mecamylamine or co-incubation of atropine and mecamylamine did not alter the intracellular $\mathrm{Ca}^{2+}$ transient amplitude (Fig. 4A), intracellular $\mathrm{Ca}^{2+}$ transient decay rate (Fig. 4B) and intracellular $\mathrm{Ca}^{2+}$ diastolic level (Fig. 4C). The effects of Ach given after $\mathrm{H}_{2} \mathrm{O}_{2}$ application in cardiomyocytes on $\mathrm{Ca}^{2+}$ transient tracing shape is shown in Fig. 4D.

\section{Discussion}

The major findings of the present study are as follows. In cardiomyocytes under $\mathrm{H}_{2} \mathrm{O}_{2}$-induced oxidative stress, pre-treated cardiomyocytes with ACh (1) did not alter the intracellular diastolic $\mathrm{Ca}^{2+}$ level, (2) attenuated the reduction of intracellular $\mathrm{Ca}^{2+}$ transient amplitude and intracellular $\mathrm{Ca}^{2+}$ transient decay rate are caused by $\mathrm{H}_{2} \mathrm{O}_{2}$, (3) both atropine (a muscarinic acetylcholine receptor blocker) and mecamylamine (a nicotinic acetylcholine receptor blocker) significantly decreased the protective effects of ACh on the intracellular $\mathrm{Ca}^{2+}$ regulation, (4) the combination of muscarinic and nicotinic blockers completely abolished the protective effects of ACh on intracellular $\mathrm{Ca}^{2+}$ transient amplitude and decay rate. Finally, ACh given after $\mathrm{H}_{2} \mathrm{O}_{2}$ application did not improve intracellular $\mathrm{Ca}^{2+}$ regulation impaired by oxidative stress.

The present study demonstrated that $\mathrm{H}_{2} \mathrm{O}_{2}$ application impaired intracellular $\mathrm{Ca}^{2+}$ regulation in isolated cardiomyocytes. Both intracellular $\mathrm{Ca}^{2+}$ transient amplitude and 


\section{Cellular Physiology Cell Physiol Biochem 2016;39:341-349

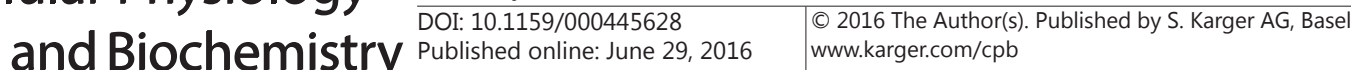 \\ Palee et al.: Acetylcholine Attenuates $\mathrm{H}_{2} \mathrm{O}_{2}$-Induced Calcium Dyshomeostasis}

decay rate significantly reduced in $\mathrm{H}_{2} \mathrm{O}_{2}$ treated group. Our findings are consistent with the previous study in the rat ventricular myocyte which demonstrated that $\mathrm{H}_{2} \mathrm{O}_{2}$ significantly decreased both intracellular $\mathrm{Ca}^{2+}$ transient amplitude and the rate of systolic $\mathrm{Ca}^{2+}$ removal [23]. The reduction of intracellular $\mathrm{Ca}^{2+}$ removal due to the impaired SERCA activity was shown to lead to intracellular $\mathrm{Ca}^{2+}$ overload and cardiac dysfunction [23]. Previous study also demonstrated that $\mathrm{ACh}$ is required for the maintenance of the cardiac $\mathrm{Ca}^{2+}$ cycling proteins [24]. Specifically, lack of ACh significantly reduces intracellular $\mathrm{Ca}^{2+}$ transient amplitude and intracellular $\mathrm{Ca}^{2+}$ transient decay rate, suggesting that ACh is necessary for the maintenance of intracellular $\mathrm{Ca}^{2+}$ transient regulation [24].

The timing of ACh application was also crucial for its protective effect in our study in which early application of ACh prior to $\mathrm{H}_{2} \mathrm{O}_{2}$ application showed better benefit. This may explain the findings reported previously in a swine model of I/R injury that vagus nerve stimulation (VNS) applied early at the onset of the ischemic period exerts cardioprotection against I/R injury $[12,13]$. However, VNS applied at the onset of reperfusion did not produce cardioprotection against I/R injury, suggesting that the timing of VNS application with respect to the onset of myocardial ischemia is an important determinant factor [13].

It has been shown previously that ACh significantly decreased both $\mathrm{Ca}^{2+}$ transient amplitude and decay rate by reducing cAMP-PKA-dependent phosphorylation of ryanodine receptors and phospholamban, leading to the reduced open probability of the ryanodine receptor, and slower SERCA-mediated intracellular $\mathrm{Ca}^{2+}$ re-uptake into the SR, respectively [25]. However, $\mathrm{H}_{2} \mathrm{O}_{2}$ has been shown to decrease SERCA and NCX activities [26, 27] by inhibiting PKC activities, leading to the alteration of the intracellular $\mathrm{Ca}^{2+}$ homeostasis. Thus, ACh and $\mathrm{H}_{2} \mathrm{O}_{2}$ mediate the intracellular $\mathrm{Ca}^{2+}$ homeostasis through differentsignaling pathways. Although the potential mechanism by which ACh prestimulation protects cardiomyocytes against $\mathrm{H}_{2} \mathrm{O}_{2}$-induced intracellular $\mathrm{Ca}^{2+}$ dyshomeostasis are unclear, it might be due to the ability of ACh to protect cardiomyocytes from oxidative stress-related damage and prevent cardiac mitochondrial dysfunction as shown by previous studies. In rat's cardiomyoblasts, ACh exerted cardioprotection against oxidative injury through Fox03a/PGC- $1 \alpha$ signaling pathway [28]. Moreover, in endothelial cells, activation of $\alpha 7$ nicotinic acetylcholine receptor protected against oxidant stress damage through reducing vascular peroxidase- 1 in a JNK signaling-dependent manner [29]. These protective mechanisms of ACh could be responsible for improved intracellular calcium homeostasis observed in the present study.

The important roles of both muscarinic and nicotinic cholinergic receptors on the intracellular calcium handling have been demonstrated in this study. We found that while either atropine (a muscarinic acetylcholine receptor blocker) or mecamylamine (a nicotinic acetylcholine receptor blocker) significantly decreased the protective effects of ACh on intracellular $\mathrm{Ca}^{2+}$ regulation, the combination of atropine and mecamylamine completely abolished the protective effects of ACh on intracellular $\mathrm{Ca}^{2+}$ transient amplitude and decay rate. These findings emphasize that ACh exerts the beneficial effect on intracellular $\mathrm{Ca}^{2+}$ regulation through both muscarinic and nicotinic receptors.

Study Limitations: In the present study, we only measured the $\mathrm{Ca}^{2+}$ transient at the beginning and at the end of the study. Future study is needed to investigate the changes of calcium transient over times. Although we did not assess the sarcoplasmic reticulum calcium content, previous studies demonstrated that the sarcoplasmic reticulum $\mathrm{Ca}^{2+}$ content was directly proportionate to intracellular $\mathrm{Ca}^{2+}$ transient amplitude and intracellular $\mathrm{Ca}^{2+}$ transient decay rate $[30,31]$.

\section{Conclusion}

Acetylcholine protects cardiomyocytes against $\mathrm{H}_{2} \mathrm{O}_{2}$-induced intracellular $\mathrm{Ca}^{2+}$ dyshomeostasis through the activation of both muscarinic and nicotinic receptors. These findings provide the important information regarding the mechanism underlying the cardioprotective effect of ACh against intracellular $\mathrm{Ca}^{2+}$ dyshomeostasis under oxidative 


\section{Cellular Physiology Cell Physiol Biochem 2016;39:341-349

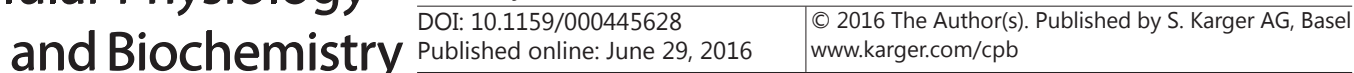 \\ Palee et al.: Acetylcholine Attenuates $\mathrm{H}_{2} \mathrm{O}_{2}$-Induced Calcium Dyshomeostasis}

stress. Moreover, these roles of ACh may explain the cardioprotective benefits of VNS during I/R injury observed in the preclinical studies.

\section{Disclosure Statement}

The authors declare no conflict of interest.

\section{Acknowledgements}

This work was supported by the Thailand Research Fund grants TRG5780007 (SP), RSA5880015 (KS) and BRG5780016 (SCC), the NSTDA Research Chair grant from the National Science and Technology Development Agency Thailand (NC), and the Chiang Mai University Center of Excellence Award (NC).

\section{References}

1 Dhalla NS, Golfman L, Takeda S, Takeda N, Nagano M: Evidence for the role of oxidative stress in acute ischemic heart disease: a brief review. Can J Cardiol 1999;15:587-593.

2 Ferrari R, Guardigli G, Mele D, Percoco GF, Ceconi C, Curello S: Oxidative stress during myocardial ischaemia and heart failure. Curr Pharm Des 2004;10:1699-1711.

3 Rodrigo R, Libuy M, Feliu F, Hasson D: Oxidative stress-related biomarkers in essential hypertension and ischemia-reperfusion myocardial damage. Dis Markers 2013;35:773-790.

4 Bopassa JC: Protection of the ischemic myocardium during the reperfusion: between hope and reality. Am J Cardiovasc Dis 2012;2:223-236.

5 Monassier JP: Reperfusion injury in acute myocardial infarction. From bench to cath lab. Part i: basic considerations. Arch Cardiovasc Dis 2008;101:491-500.

6 Hausenloy DJ, Yellon DM: Reperfusion injury salvage kinase signalling: taking a risk for cardioprotection. Heart Fail Rev 2007;12:217-234.

7 Kakinuma Y, Ando M, Kuwabara M, Katare RG, Okudela K, Kobayashi M, Sato T: Acetylcholine from vagal stimulation protects cardiomyocytes against ischemia and hypoxia involving additive non-hypoxic induction of HIF-1alpha. FEBS Lett 2005;579:2111-2118.

8 Calvillo L, Vanoli E, Andreoli E, Besana A, Omodeo E, Gnecchi M, Zerbi P, Vago G, Busca G, Schwartz PJ: Vagal stimulation, through its nicotinic action, limits infarct size and the inflammatory response to myocardial ischemia and reperfusion. J Cardiovasc Pharmacol 2011;58:500-507.

9 Katare RG, Ando M, Kakinuma Y, Arikawa M, Yamasaki F, Sato T: Differential regulation of tnf receptors by vagal nerve stimulation protects heart against acute ischemic injury. J Mol Cell Cardiol 2010;49:234-244.

10 Li W, Olshansky B: Inflammatory cytokines and nitric oxide in heart failure and potential modulation by vagus nerve stimulation. Heart Fail Rev 2011;16:137-145.

11 Uemura K, Zheng C, Li M, Kawada T, Sugimachi M: Early short-term vagal nerve stimulation attenuates cardiac remodeling after reperfused myocardial infarction. J Card Fail 2010;16:689-699.

12 Shinlapawittayatorn K, Chinda K, Palee S, Surinkaew S, Thunsiri K, Weerateerangkul P, Chattipakorn S, KenKnight BH, Chattipakorn N: Low-amplitude, left vagus nerve stimulation significantly attenuates ventricular dysfunction and infarct size through prevention of mitochondrial dysfunction during acute ischemia-reperfusion injury. Heart Rhythm 2013;10:1700-1707.

13 Shinlapawittayatorn K, Chinda K, Palee S, Surinkaew S, Kumfu S, Kumphune S, Chattipakorn S, KenKnight BH, Chattipakorn N: Vagus nerve stimulation initiated late during ischemia, but not reperfusion, exerts cardioprotection via amelioration of cardiac mitochondrial dysfunction. Heart Rhythm 2014;11:22782287.

14 Palee S, Weerateerangkul P, Chinda K, Chattipakorn SC, Chattipakorn N: Mechanisms responsible for beneficial and adverse effects of rosiglitazone in a rat model of acute cardiac ischaemia-reperfusion. Exp Physiol 2013;98:1028-1037. 


\section{Cellular Physiology Cell Physiol Biochem 2016;39:341-349

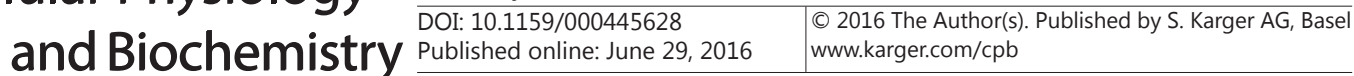 \\ Palee et al.: Acetylcholine Attenuates $\mathrm{H}_{2} \mathrm{O}_{2}$-Induced Calcium Dyshomeostasis}

15 Weerateerangkul P, Palee S, Chinda K, Chattipakorn SC, Chattipakorn N: Effects of kaempferia parviflora Wall. Ex. Baker and sildenafil citrate on cGMP level, cardiac function, and intracellular Ca2+ regulation in rat hearts. J Cardiovasc Pharmacol 2012;60:299-309.

$16 \mathrm{Xu} \mathrm{YJ,} \mathrm{Shao} \mathrm{Q,} \mathrm{Dhalla} \mathrm{NS:} \mathrm{Fura-2} \mathrm{fluorescent} \mathrm{technique} \mathrm{for} \mathrm{the} \mathrm{assessment} \mathrm{of} \mathrm{Ca2+} \mathrm{homeostasis} \mathrm{in}$ cardiomyocytes. Mol Cell Biochem 1997;172:149-157.

17 Palee S, Weerateerangkul P, Surinkeaw S, Chattipakorn S, Chattipakorn N: Effect of rosiglitazone on cardiac electrophysiology, infarct size and mitochondrial function in ischaemia and reperfusion of swine and rat heart. Exp Physiol 2011;96:778-789.

18 Grynkiewicz G, Poenie M, Tsien RY: A new generation of Ca2+ indicators with greatly improved fluorescence properties. J Biol Chem 1985;260:3440-3450.

19 Waldeck-Weiermair M, Bischof H, Blass S, Deak AT, Klec C, Graier T, Roller C, Rost R, Eroglu E, Gottschalk B, Hofmann NA, Graier WF, Malli R: Generation of red-shifted cameleons for imaging Ca2+ dynamics of the endoplasmic reticulum. Sensors (Basel) 2015;15:13052-13068.

20 Bootman MD, Rietdorf K, Collins T, Walker S, Sanderson M: Ca2+-sensitive fluorescent dyes and intracellular Ca2+ imaging. Cold Spring Harb Protoc 2013;2013:83-99.

21 Kaminishi T, Matsuoka T, Yanagishita T, Kako KJ: Increase vs. Decrease of calcium uptake by isolated heart cells induced by H2O2 vs. HOCl. Am J Physiol Cell Physiol 1989;256:C598-607.

22 Josephson RA, Silverman HS, Lakatta EG, Stern MD, Zweier JL: Study of the mechanisms of hydrogen peroxide and hydroxyl free radical-induced cellular injury and calcium overload in cardiac myocytes. J Biol Chem 1991;266:2354-2361.

23 Greensmith DJ, Eisner DA, Nirmalan M: The effects of hydrogen peroxide on intracellular calcium handling and contractility in the rat ventricular myocyte. Cell Calcium 2010;48:341-351.

24 Roy A, Fields WC, Rocha-Resende C, Resende RR, Guatimosim S, Prado VF, Gros R, Prado MA: Cardiomyocyte-secreted acetylcholine is required for maintenance of homeostasis in the heart. FASEB J 2013;27:5072-5082.

25 van Borren MM, Verkerk AO, Wilders R, Hajji N, Zegers JG, Bourier J, Tan HL, Verheijck EE, Peters SL, Alewijnse AE, Ravesloot JH: Effects of muscarinic receptor stimulation on Ca2+ transient, camp production and pacemaker frequency of rabbit sinoatrial node cells. Basic Res Cardiol 2010;105:73-87.

26 Reeves JP, Bailey CA, Hale CC: Redox modification of sodium-calcium exchange activity in cardiac sarcolemmal vesicles. J Biol Chem 1986;261:4948-4955.

27 Goldhaber JI: Free radicals enhance Na+/Ca2+ exchange in ventricular myocytes. Am J Physiol 1996;271:H823-833.

28 Sun L, Zang WJ, Wang H, Zhao M, Yu XJ, He X, Miao Y, Zhou J: Acetylcholine promotes ROS detoxification against hypoxia/reoxygenation-induced oxidative stress through FoxO3a/PGC-1 $\alpha$ dependent superoxide dismutase. Cell Physiol Biochem 2014;34:1614-1625.

29 Li DJ, Zhao T, Xin RJ, Wang YY, Fei YB, Shen FM: Activation of $\alpha 7$ nicotinic acetylcholine receptor protects against oxidant stress damage through reducing vascular peroxidase-1 in a JNK signaling-dependent manner in endothelial cells. Cell Physiol Biochem 2014;33:468-478.

30 Sankaranarayanan R, Li Y, Greensmith DJ, Eisner DA, Venetucci L: Biphasic decay of the Ca transient results from increased sarcoplasmic reticulum Ca leak. J Physiol 2016;594:611-623.

31 Feridooni HA, Dibb KM, Howlett SE: How cardiomyocyte excitation, calcium release and contraction become altered with age. J Mol Cell Cardiol 2015;83:62-72. 